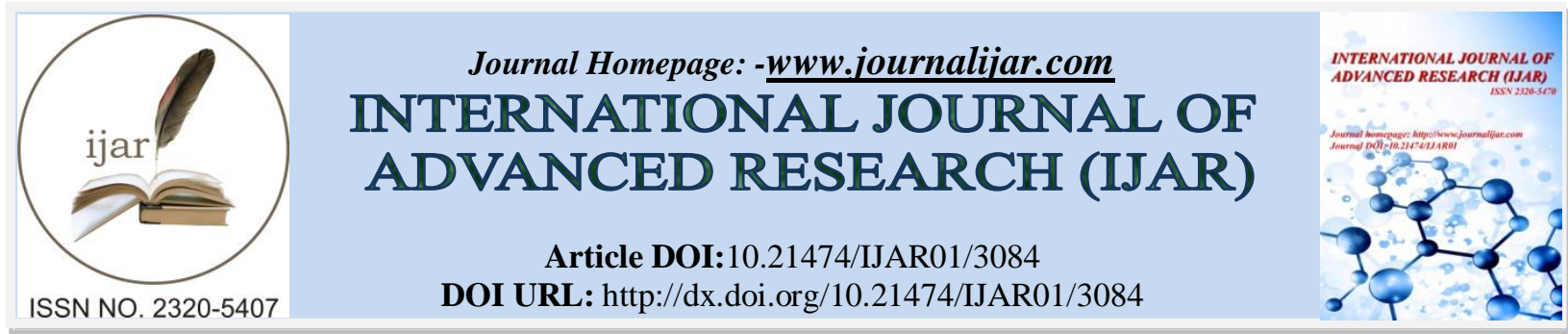

\title{
Abstract \\ THE PREVALENCE OF HTN AMONG WORKING PERSONNEL, FACULTY OF EDUCATION AT TAIBAH UNIVERSITY.
}

Abdullah Al-johani, Abdullah Allam, Ibrahim Al-sehli, Marwan Al-Lohabi and Mohammed Sa'ad. Under the supervision of Dr. Khalid Qasim.

\section{Manuscript Info}

Manuscript History

Received: 03 November 2016

Final Accepted: 28 December 2016

Published: January 2017

\section{Abstract}

Introduction: Hypertensive is defined as an abnormal elevation in diastolic pressure and/or systolic pressure; mean arterial pressure is also elevated in hypertension, but it is not usually measured in people. In past years, the diastolic value was emphasized in assessing hypertension. However, elevations in systolic pressure ("systolic hypertension") are also associated with increased incidence of coronary and cerebrovascular disease (e.g., stroke). Therefore, we now recognize that both systolic and diastolic pressure values are important to note. High blood pressure, termed "hypertension" is a condition that afflicts almost 1 billion people worldwide and is a leading cause of morbidity and mortality. About $26 \%$ of Saudis are hypertensive. For males, the prevalence of hypertension is $28.6 \%$, while for females; the prevalence is significantly lower at $23.9 \%$.The urban population show significantly higher prevalence of hypertension of $27.9 \%$, compared to rural population's prevalence of $22.4 \%$. One-third of them are not even aware they are hypertensive.

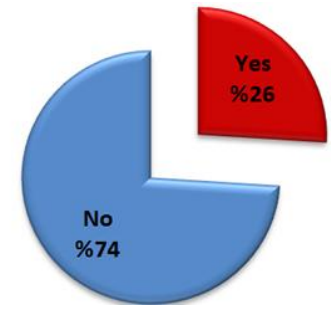

The Prevalence of hypertension in Saudi Arabia is $26 \%$

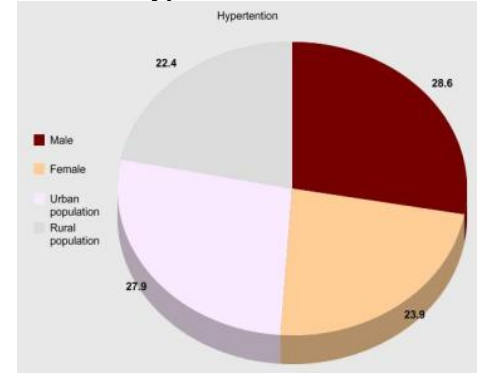

The following represents different stages of hypertension: 


\begin{tabular}{|c|c|c|}
\hline Classification & $\begin{array}{c}\text { Systolic } \\
(\mathrm{mmHg})\end{array}$ & $\begin{array}{c}\text { Diastolic } \\
(\mathrm{mmHg})\end{array}$ \\
\hline Normal & $<120$ & $<80$ \\
\hline Prehypertension & $120-139$ & $80-89$ \\
\hline Stage 1 & $140-159$ & $90-99$ \\
\hline Stage 2 & $>160$ & $>100$ \\
\hline
\end{tabular}

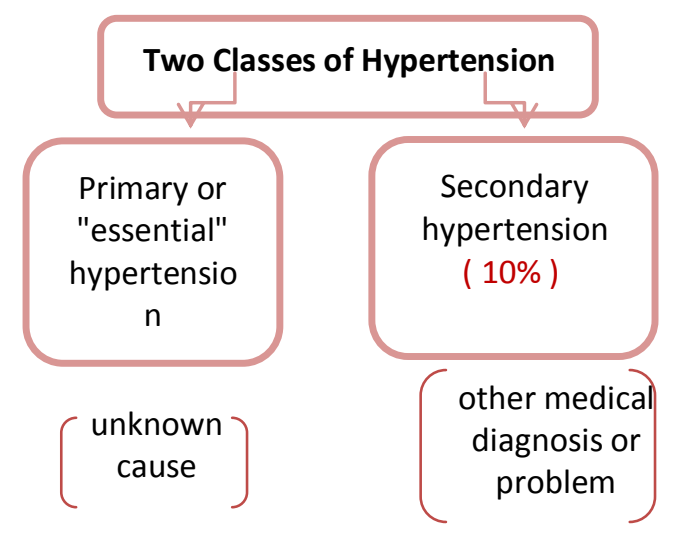

Objectives: The study aims to decrease HTN among working personnelin Al-medina. Also to determine the prevalence of HTN among working personnel, faculty of education at Taibah University and Identify associated risk factors that may contribute in the disease.

Research question: What is the prevalence of hypertension among working personnel, faculty of education at Taibah University?

Methodology: Our research is considered a type of observational study which is cross sectional (survey, prevalence) study. We started our research by doing survey on working personnel, faculty of education (30 subjects/men) who are between $25-55$. The data collected included the main risk factors of hypertension (age, exercise, smoking, stress, and family history) by self- administrated questionnaires. We aimed to get completeness and avoid complexity. We have made sure that all of collected data are highly confidential and for the purpose of scientific research only. The statistical analysis was conducted by SSPS program.

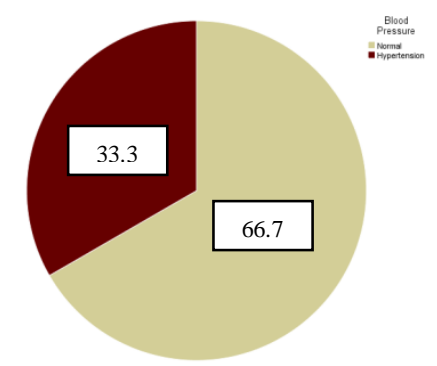

The Prevalence of hypertension among working personnel is $33.3 \%$ Age \& hypertension

\begin{tabular}{|l|c|c|c|c|}
\hline \multicolumn{2}{|c|}{} & \multicolumn{3}{|c|}{ AGE } \\
\cline { 3 - 5 } \multicolumn{2}{|c|}{} & $>45$ & $45-30$ & $<30$ \\
\cline { 3 - 5 } & Count & Count & Count \\
\hline \multirow{2}{*}{ Blood Pressure } & Normal & 7 & 2 & 10 \\
\cline { 2 - 5 } & Hypertension & 5 & 1 & 4 \\
\hline
\end{tabular}

The risk of hypertension may increases with age 


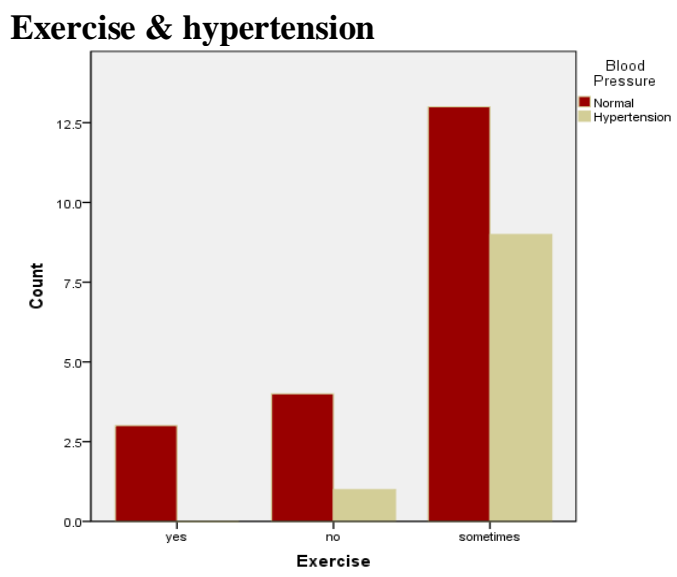

Exercise may decreases the risk of hypertension

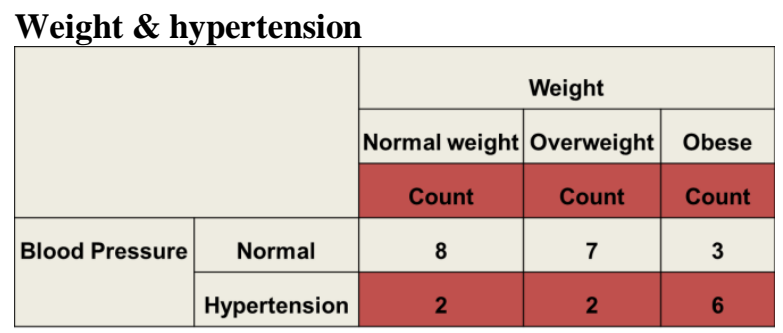

Obesity may increases the risk of hypertension

\section{Family history \& hypertension}

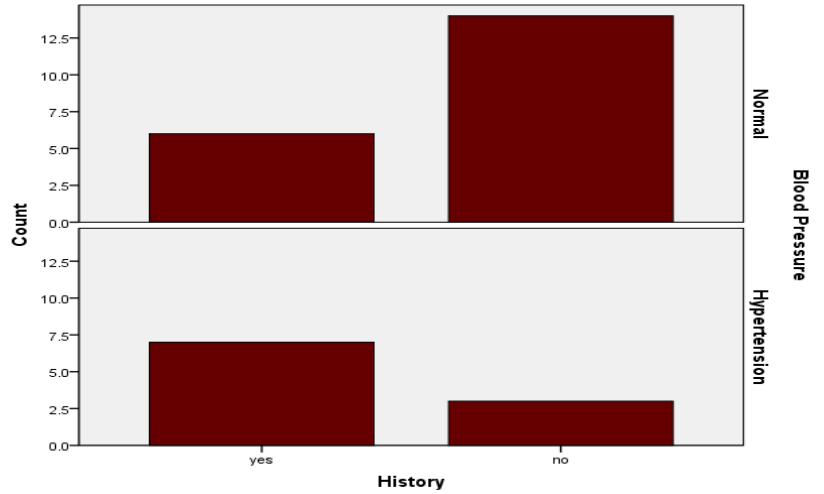

Hypertension tends to run in families.

\section{Smoking \& hypertension}

\begin{tabular}{|l|c|c|c|}
\hline \multicolumn{2}{|c|}{} & \multicolumn{2}{|c|}{ Smoking } \\
\cline { 3 - 4 } & yes & no \\
\cline { 2 - 4 } & Count & Count \\
\hline \multirow{2}{*}{ Blood Pressure } & Normal & 9 & 11 \\
\cline { 2 - 4 } & Hypertension & 7 & 3 \\
\hline
\end{tabular}

smoking may increases the risk of hypertension.

Results: The prevalence of HTN among working personnel, faculty of education at Taibah University is $33.3 \%$. According to the study exercise may decrease the risk of hypertension. The main risk factors are age, obesity, family history and cigarette smoking. 
Conclusion: The research conducted indicates a higher prevalence in working employees at the University of Taibah. than in the general population. The prevalence is $\%$ higher than in the general population. A factor that may contribute to the higher prevalence is the small sample size of our research. Also, another factor may be the type of job that is performed by the employees of the university, the stress level of this form of job may have increased the prevalence and also the sendentary level of this type of job may have increased the prevalence as well. It is a concern that may need to be addressed to decrease the likelihood of heart disease in this population.

Copy Right, IJAR, 2016,. All rights reserved. 